\title{
DESIGN AND SCREENING OF GALLIC ACID DERIVATIVES AS INHIBITORS OF MALARIAL DIHYDROFOLATE REDUCTASE BY IN SILICO DOCKING
}

\author{
ADE ARSIANTI ${ }^{1 *}$, HENDRI ASTUTY ${ }^{2}$, FADILAH $^{1}$, ANTON BAHTIAR $^{3}$, HIROKI TANIMOTO ${ }^{4}$, KIYOMI KAKIUCHI ${ }^{4}$ \\ ${ }^{1}$ Department of Medical Chemistry, Faculty of Medicine, University of Indonesia, Jalan, Salemba Raya 6 Jakarta 10430 , Indonesia. \\ ${ }^{2}$ Department of Parasitology, Faculty of Medicine, University of Indonesia, Jalan, Salemba Raya 6 Jakarta 10430, Indonesia. ${ }^{3}$ Department \\ of Pharmacology, Faculty of Pharmacy, University of Indonesia, Kampus UI, Depok, West Java, Indonesia. ${ }^{4}$ Department of Pharmacology, \\ Graduate School of Materials Science, Nara Institute of Science and Technology, 8916-5 Takayama-cho, Ikoma, Nara, Japan. \\ Email: arsi_ade2002@yahoo.com
}

Received: 17 October 2016, Revised and Accepted: 28 October 2016

ABSTRACT

Objective: Malaria is an infection disease caused by Plasmodium parasite with high prevalence in tropic and subtropic countries. The aim of this work was to design and screening of gallic acid derivatives as inhibitors of malarial dihydrofolate reductase (DHFR) by in silico docking.

Methods: The derivatives were designed by expanding the carboxyl group of gallic acid with open-chain moiety of L-threonine-allyl esters, as well as to modify the hydroxyl groups on the aromatic ring of gallic acid with methoxyl group in the derivatives. In silico approach has been utilized in finding the potential antimalaria of gallic acid derivatives. Fourteen gallic acid derivatives (compound 2-15) were modeled into three-dimensional (3D) structures by ACD Labs software. Geometry optimization and minimization of energy 3D structure of gallic acid derivatives as ligands using the MOE software. Docking process and amino acid analysis were executed using MOE software.

Results: In silico docking study resulted in the three top-ranked compounds, namely, compound 5, 8, and 12 . Among those three top-ranked compounds, compound 12 (octyl gallate) exhibited the strongest interaction and greatest inhibitory activity against the receptor of malarial DHFR.

Conclusion Our results clearly demonstrated that compound 12 (octyl gallate) could be developed as a promising candidate for the new antimalarial agent.

Keywords: Design, Screening, Gallic acid derivatives, Antimalaria, Dihydrofolate reductase, In silico docking.

(C) 2017 The Authors. Published by Innovare Academic Sciences Pvt Ltd. This is an open access article under the CC BY license (http://creativecommons. org/licenses/by/4. 0/) DOI: http://dx.doi.org/10.22159/ajpcr.2017.v10i2.15712

\section{INTRODUCTION}

Malaria is one of the Plasmodium parasite infections which found in many tropical and subtropical countries. According to the WHO (2010), around 2.3-3.3 billion people suffered in malaria, especially in Africa, Asia, Middle East, Latin America, and some parts of Europe [1]. Particularly, children under age 5 and pregnant women are people with the most severe infection of malaria [2]. In Indonesia, there are 396 districts of malaria endemic and approximately $45 \%$ of the population live in areas at risk of malaria [3]. Since 2010, the directorate general of disease control and environmental sanitation, Ministry of health, Republic of Indonesia, has been used annual parasite incidence (API) to express incidence of malaria in Indonesia. Papua, West Papua, and East Nusa Tenggara are the provinces with the highest malarial incidence with API 18.03, 17.86, and 12.14/1000 population, respectively. Strategic Plan of the Ministry of Health Republic of Indonesia in 2010-2014 targeted to reduce morbidity of malaria from 2 to $1 / 1000$ population [4,5]. There are four species of the genus Plasmodium that can cause infections in humans, namely, Plasmodium falciparum, plasmodium vivax, Plasmodium malariae, and Plasmodium ovale. Among these four types, the $P$. falciparum that causes malaria falciparum is the most dangerous type because it can cause serious complications which lead to the death [6].

Currently, the treatment of malaria caused by $P$. falciparum parasite relies on the use of chloroquine or synergistic combination of aminoquinoline-antifolate and sulfadoxine-pyrimethamine. However, a recent study reported that antimalarial drugs have shown resistance which leads to the decreasing in its effectiveness [7]. This fact indicated the new antimalarial drugs that are more potent, more effective, and safer are required. Gallic acid (1) is naturally obtained compound which showed biological activity as an antioxidant, antifungal, antiviral, anti-inflammatory, and anticancer. It has been reported that gallic acid significantly inhibited the growth of viruses and bacteria, as well as induced apoptosis of cancer cells [8-10]. Previous researchers also reported that gallic acid (1) and some of alkyl ester gallate showed antimalarial activity. Gallic acid which is one of the main components in oregano (Origanum compactum) was reported to have antimalarial activity [11]. Researcher from Italy, Sannela et al., reported that gallic acid derivatives containing in green tea, namely, epigallocatechin-3gallate, and epicatechin gallate showed strong antimalarial activity against P. falciparum [12]. In 1999, Murphy and Lang-Unnasch reported that the combination of alkyl ester gallate, i.e. propyl gallate with atovaquone has antimalarial activity more powerful than the combination of atovaquone with gallic acid [13]. This result revealed that the alkyl ester derivative of gallic acid (alkyl ester gallate) could be developed as an antimalarial drug. The strong antimalarial activity of alkyl ester gallate prompted us to carry out research that is aimed to design a series of alkyl ester derivative of gallic acid, compound 2-15 (Fig. 1), as well as to study the interaction of the derivatives with receptor target of malarial dihydrofolate reductase (DHFR) by computational in silico molecular docking. The three best compounds which showed the strongest interaction with receptor target of malarial DHFR will be synthesized and will be examined its in vitro and in vivo antimalarial activity in our next research project.

Many researchers have been completed the study on the interaction of compounds with antimalaria drug targets by in silico molecular 


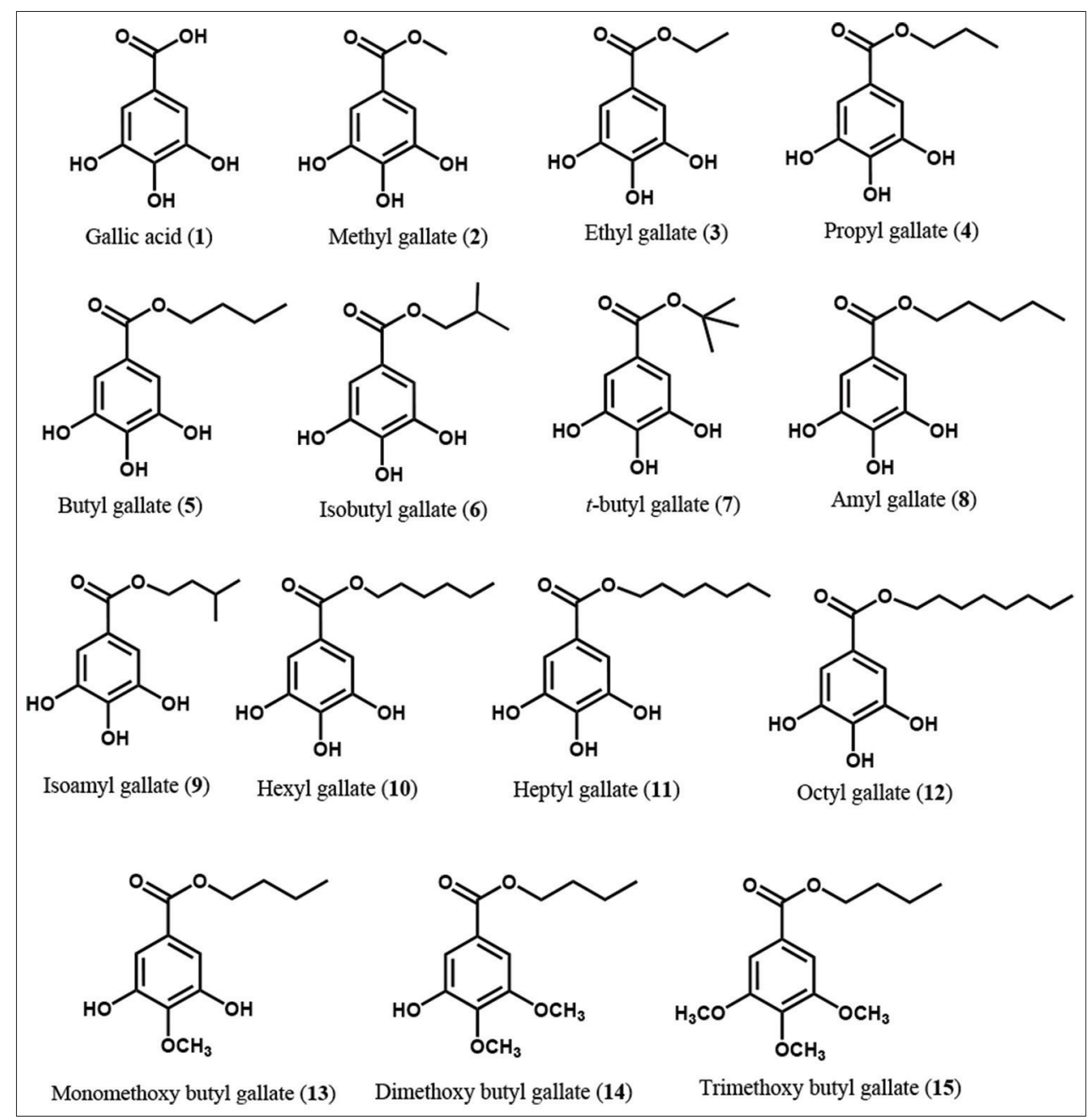

Fig. 1: Chemical structure of gallic acid (1) and its derivatives (2-15)

docking $[14,15]$. Sharma and Chetia (2013) conducted docking studies on quinine analog for plasmepsin II of malarial parasite [16]. Lulu et al. (2015) have been accomplished in silico docking study of 240 antimalarial compounds with active site of $P$. falciparum chorismate synthase protein [17]. Ravi and Ragunathan (2016) conducted in silico analysis of alien and microdontin with P. falciparum calcium-dependent protein kinase [18]. In 2014, we conducted in silico molecular docking study on antimycin A analogs as inhibitors of antiapoptotic Bcl-2 of breast cancer [19]. Recently, In 2016, we have reported in silico molecular docking studies of opened-chain analogs of antimycin $\mathrm{A}_{3}$ as caspases inhibitors of apoptosis in colorectal cancer [20]. In this work, as a part our continuing research to develop computer-aided drug design and screening by docking approach, we conduct in silico study and screening of 14 gallic acid derivatives as inhibitors of malarial DHFR.

\section{METHODS}

\section{Design structure of gallic acid derivatives}

A series of gallic acid derivatives were designed by modifying the carboxyl group of gallic acid with alkyl ester group which have one to eight linear aliphatic carbon chains in derivative $2,3,4,5,8,10$, $11,12,13,14$, and 15 and have a branched aliphatic carbon chain in derivative 6,7 , and 9 . The previous studies showed that the methylation of the hydroxyl group on the aromatic ring of gallic acid will enhance the antiviral activity, so in this study, we modify the hydroxyl groups on the aromatic ring of butyl gallate become monomethoxy butyl gallate in derivative 13, 3,5-Dihydroxy-4-methoxy benzoic acid butyl ester in derivative 14 and trimethoxy butyl gallate in derivative 15 .
These modifications are expected to increase antimalarial activity of derivatives 2-15 as growth inhibitors Plasmodium falciparum.

\section{Structure preparation}

Gallic acid derivatives were modeled into three-dimensional (3D) structures. The modeling is performed using ACD Labs software.

\section{Geometry optimization and energy minimization 3D structure of} ligands

Geometry optimization and minimization of energy 3D structure of gallic acid derivatives (ligands) using the MOE software that runs on a single computer Intel Pentium Dual Core. The algorithm used is the conjugate gradient Polak-Ribiere with maximum convergence root mean square gradient of $0.01 \mathrm{kcal} / \mathrm{mol}$ and parameters $\AA$ molecular mechanics force field MMFFx.

\section{In silico docking of gallic acid derivative on receptor DHFR}

The process of in silico docking begins with file preparation using a docking program in MOE software. Both molecules of gallic acid derivative (then called ligand) and the enzyme, polar hydrogen, and Gasteiger charge were added, and nonpolar hydrogen was merged. Ligand and enzyme were stored in molecular format file for later use in the preparation parameters. Grid box used was $60 \times 60 \times 60$ with a grid spacing of 0.375 Á. Docking calculations executed by the algorithm parameters Lamarckian genetic algorithm with a population size of 150, 10 million energy evaluation and repetition (engine runs) as much as 100 times. These parameters are stored in a format MOE as a file to be used to carry out the process of docking. Docking process is executed using MOE software. 
In silico docking analysis

The results of in silico docking calculations can be seen in output in txt format. Determination of heme-ligand conformation results of docking is done by selecting ligand conformations which have lowest binding affinity energy of the group (cluster) with the largest number of population with a limit of a standard deviation of $1.5 \AA$. Energy binding and inhibition constants docking results can be seen in output in notepad format. Preferred complex is a complex that has smallest binding affinity energy and inhibition constants which subsequently used for further analysis. Hydrogen bonding that occurs in complex heme-ligand docking best results is identified using MOE software with input files in formats.pdb. Contact residue of heme-ligand complex from docking results is identified using MOE software.

\section{RESULTS AND DISCUSSION}

\section{In silico molecular docking of gallic acid derivatives}

Gallic acid (1) and fourteen derivatives (2-15) were simulated using in silico molecular docking on target protein of malarial DHFR P. falciparum. The results are displayed in Table 1 . The best interaction between the compound and the receptor DHFR was assessed based on low $\Delta \mathrm{G}$ binding energy, high $\mathrm{p} K_{\mathrm{i}}$ affinity, and a number of hydrogen acceptor/hydrogen donors (hydrogen bonding interaction) to the catalytic site of DHFR target protein.

As shown in Table 1, compared to gallic acid, the derivative compounds $12,8,5,10,11,9,7$, and 6 and methoxy butyl gallate 13, 14, and 15, exhibited lower $\Delta G$ value, indicating that these derivatives have a stronger conformational stability against malarial DHFR. Compared to butyl gallate (5), derivatives 13,14 , and 15 which have monomethoxy group, dimethoxy group, and trimethoxy group on the aromatic ring, respectively, showed higher $\Delta \mathrm{G}$ value and lower pKi value, suggesting that replacing the hydroxyl group in 5 with methoxy group in 13,14 , and 15 resulted in increasing of stability and affinity against receptor DHFR. Furthermore, compared to derivative 6 (isobutyl gallate) and derivative 7 (tert butyl gallate) which have branched aliphatic carbon chain, derivative 5 (butyl gallate) which has linear aliphatic carbon chain, exhibited higher pKi value and stronger hydrogen acceptor/ hydrogen donor interactions. Similar results also observed between derivative 8 (amyl gallate) and derivative 9 (isoamyl gallate). Compared to derivative 9 which has branched structure, derivative 8 with linear structure showed higher stability, higher affinity, and stronger hydrogen acceptor/hydrogen donor interactions on receptor malarial DHFR. These results revealed that the existence of alkyl ester group with linear structure in alkyl ester gallate is more important for antimalarial activity compared to alkyl ester group with branched structure. Moreover, in silico docking of the derivatives compound 2-12 produced the three top-ranked derivatives compounds, namely, derivatives 12 (octyl gallate), 8 (amyl gallate), and 5 (butyl gallate) as marked in red color that showed lower $\Delta \mathrm{G}$ binding energy value, higher $\mathrm{pKi}$ value, and a higher number of hydrogen bonding interaction than the others compounds. The $\Delta \mathrm{G}$ values of derivatives 12,8 , and 5 are -12.8806 , -12.7127 , and $-9.7506 \mathrm{Kkcal} / \mathrm{mol}$, respectively, which are better than gallic acid (1), with a $\Delta G$ value of $-9.5473 \mathrm{Kcal} / \mathrm{mol}$. These results showed that compared to gallic acid, those three top-ranked derivatives will form a more stable complex with DHFR as well as be able to inhibit and reduce the activity of DHFR better than gallic acid. The pKi value of the three top-ranked derivatives is higher than gallic acid, indicating that they have a higher affinity and interact effectively with the target DHFR. Except the number of hydrogen acceptor/hydrogen donor interactions, all of those three top-ranked derivatives have a $\log \mathrm{P}$ value higher than gallic acid (log P: -0.883). Based on Lipinski rule, the hydrophobicity properties of drugs or compounds that can penetrate the cell membrane is in the range of 1-5. Thus, the $\log \mathrm{P}$ value of gallic acid $<1$ indicated that gallic acid is hydrophilic and it will be difficult to penetrate the cell membrane. Contrast with gallic acid, the three top-ranked compounds demonstrated higher hydrophobicity properties in ranging of 1.3-3.3, which could penetrate the cell membrane more easily than gallic acid and will contribute to strengthen their interaction against receptor DHFR.

\section{Ligand complex interaction of three top-ranked derivatives with receptor malarial DHFR}

Fig. 2 displays the two-dimensional and 3D ligand complex interaction of the three top-ranked derivatives 5, 8, and 12 with the receptor target malarial DHFR. As shown in Fig. 2, the three best compound derivatives 12,8 , and 5 were able to enter the target receptor binding sites of DHFR and changing its conformation. Thus, derivative 12, 8, and 5 showed a strong inhibitory activity against receptor malarial DHFR. Among the three top-ranked compound, derivative 12 (octyl gallate) showed the highest stability, affinity, the best hydrophobicity properties, and a greater inhibitory activity on receptor DHFR. These results indicating that the long carbon chain of alkyl ester group (eight carbon chain) in gallic acid derivative was necessary to increase its inhibitory activity against receptor of malarial DHFR.

\section{CONCLUSION}

In conclusion, we have designed and screened 14 gallic acid derivatives by in silico docking. The docking study showed derivative 12 , that is, octyl gallate with eight-long carbon chain of ester group, exhibited a greater inhibitory activity against malarial DHFR than gallic acid and others derivative. Thus, the derivative 12 (octyl gallate) should be considered as a promising candidate for the treatment of malaria infection.

\section{ACKNOWLEDGMENTS}

We thank to directorate of research and community service (DRPM) University of Indonesia, and Directorate for higher education, Ministry

Table 1: The properties of the derivatives (2-15) and gallic acid (1) on the catalytic site of DHFR

\begin{tabular}{lllll}
\hline Compound & $\boldsymbol{\Delta G}($ Kcal/mol) & pKi $(\boldsymbol{\mu M})$ & Hdon/Hacc & Log P \\
\hline 12 & -12.8806 & 9.824 & 6 & 3.321 \\
1 & -9.7473 & 7.808 & 8 & -0.833 \\
5 & -9.5506 & 7.940 & 6 & 1.370 \\
3 & -9.3146 & 7.529 & 5 & 0.980 \\
8 & -12.7127 & 8.639 & 5 & 2.150 \\
4 & -12.4858 & 7.804 & 4 & 1.760 \\
10 & -11.9845 & 7.682 & 3 & 2.541 \\
2 & -8.6675 & 6.456 & 3 & 0.590 \\
13 & -11.9899 & 7.541 & 4 & 2.063 \\
11 & -11.9253 & 7.259 & 2 & 2.931 \\
9 & -11.8890 & 7.363 & 3 & 2.006 \\
15 & -10.4856 & 6.715 & 2 & 2.662 \\
14 & -10.2458 & 7.008 & 3 & 2.366 \\
7 & -10.5877 & 7.212 & 2 & 1.759 \\
6 & -10.7084 & 6.426 & 1 & \\
\hline
\end{tabular}

DHFR: Dihydrofolate reductase 


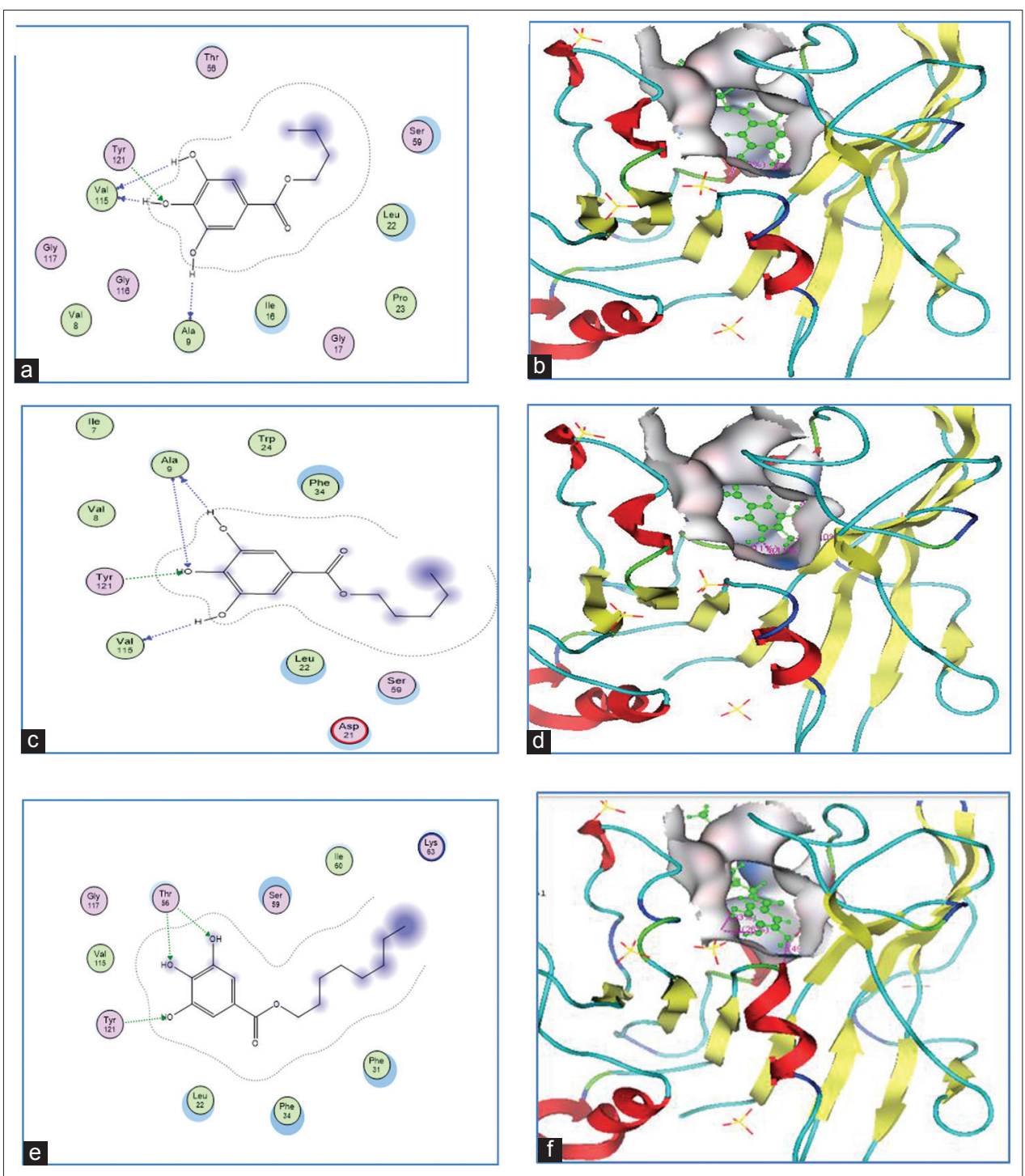

Fig. 2: Two-dimensional and three-dimensional complex interaction of derivative $5(a, b), 8(c, d)$, and 12 (e, f) with dihydrofolate reductase

of Research and Technology Republic of Indonesia, for the research grant of PUPT (Penelitian Unggulan Perguruan Tinggi, and to the Graduate School of Materials Science, Nara Institute of Science and Technology (NAIST), Japan for International Research Collaboration Program (NAIST Global Initiative Program).

\section{REFERENCES}

1. Olumes P. Guidelines for the Treatment of Malaria. $2^{\text {nd }}$ ed. Switzerland: WHO; 2011

2. Croft AM, Jacquerioz FA, Jones KL. Drugs to prevent malaria in travellers: A systematic review of randomized controlled trials. Human Parasitic Diseases 2010;2:1-19.

3. Margaret C. World Malaria Report. Switzerland: WHO; 2011.

4. Buletin Jendela Data dan Informasi. Epidemiology of Malaria in INDONESIA. Volume 1. Triwulan I. Ministry of Health Republic of Indonesia, 2011. Available from: http://www.file:///C:/users/user/ downloads/buletin-malaria.pdf

5. Indonesia National Malaria Control Program Strategic Plan 2015-2019. Ministry of Health Republic of Indonesia, 2014. Available from: http:// www.static1.1.sqspcdn.com/static/f/471029/26502872/1441109745877/ summary + of + national + malaria + control + program + stra tegic + Plan +++ 2015+edas.pdf.

6. Irianto K. Parasitologi Berbagai Penyakit Yang Mempengaruhi Kesehatan Manusia. Bandung, Indonesia: Penerbit Yrama Widya; 2009.
7. Mutabingwa TK, Anthony D, Heller A, Hallett R, Ahmed J, Drakeley C, et al. Amodiaquine alone, amodiaquine sulfadoxine-pyrimethamine, amodiaquine artesunate, and artemether-lumefantrine for outpatient treatment of malaria in Tanzanian children: A four-arm randomised effectiveness trial. Lancet 2005;365(9469):1474-80.

8. Kaur M, Velmurugan B, Rajamanickam S, Agarwal R, Agarwal C. Gallic acid, an active constituent of grape seed extract, exhibits antiproliferative, pro-apoptotic and anti-tumorigenic effects against prostate carcinoma xenograft growth in nude mice. Pharm Res 2009;26(9):2133-40.

9. Verma S, Singh A, Mishra A. Gallic acid: Molecular rival of cancer. Environ Toxicol Pharmacol 2013;35(3):473-85.

10. You BR, Moon HJ, Han YH, Park WH. Gallic acid inhibits the growth of HeLa cervical cancer cells via apoptosis and/or necrosis. Food Chem Toxicol 2010;48(5):1334-40.

11. El Babili F, Bouajila J, Souchard JP, Bertrand C, Bellvert F, Fouraste I, et al. Oregano: Chemical analysis and evaluation of its antimalarial, antioxidant, and cytotoxic activities. J Food Sci 2011;76(3):C512-8.

12. Sannela AR, Messori L, Casini A, Vincieri FF, Bilia AR, Majori G, et al. Antimalarial properties of green tea. Biol Pharm Bull 2010;31:903-7.

13. Murphy AD, Lang-Unnasch N. Alternative oxidase inhibitors potentiate the activity of atovaquone against Plasmodium falciparum. Antimicrob Agents Chemother 1999;43(3):651-4.

14. Kumar TO, Mahadevan KM, Ganapathy PS, Kumara MN. Synthesis and molecular docing study of 2 aryl/heteroaryl-6-chloroquinoline-4- 
carboxylic acids with plasmodium LDH receptor. Int J Pharm Pharm Sci 2014;7(1):431-7.

15. Pradeep PS, Kumar TO, Prashantha N, Mahadevan KM. Synthesis, in vitro antibacterial toxicity and molecular docking anticancer activity of novel N-[(2-chloroquinolin-3-yl)] methylidene-2-aniline Schiffs bases. Int J Curr Pharm Res 2015;7(3):37-46.

16. Sharma $P, C h e t i a D$. Docking studies on quinine analog for plasmepsin-II of malarial parasite using bioinformatics tool. Int J Pharm Pharm Sci 2013;5 Suppl 3:681-5.

17. Lulu S, Thabitha A, Priya AM, Vino S. Insignt into the molecular interaction of antimalarial compounds as potential chorismate synthase inhibitors. Asian J Pharm Clin Res 2015;8(4):45-52

18. Ravi L, Ragunathan A. Potential drug targets for aloin and microdontin: An in silico analysis. Asian J Pharm Clin Res 2016;9(2):194-6.

19. Arsianti A, Fadilah F, Kusmardi K, Tanimoto $H$, Morimoto $T$, Kakiuchi K. Design and molecular docking study of antimycin A analogues as inhibitors of anti-apoptotic Bcl-2 of breast cancer. Open J Med Chem 2014;4:79-86.

20. Fadilah F, Arsianti A, Kusmardi K, Tedjo A. Molecular docking studies of opened-chain analogues of antimycin $\mathrm{A}_{3}$ as caspases inhibitors of apoptosis in colorectal cancer. Asian J Pharm Clin Res 2016;9(3):350-2

Author Query???

AQ1: Please check the term. 